\title{
Educomunicação Socioambiental como estratégia pedagógica no ensino infantil
}

\author{
FREITAS, José Vicente de (Rio Grande, Rio Grande do Sul, Brasil) ${ }^{1 *}$ \\ FERREIRA, Felipe Nóbrega (Rio Grande, Rio Grande do Sul, Brasil) ${ }^{2 *}$ \\ 1 Universidade Federal do Rio Grande, Programa de Pós-Graduação em Educação Ambiental, \\ Instituto de Ciências Humanas e Informação \\ 2Universidade Federal do Rio Grande, Programa de Pós-Graduação em Educação Ambiental, \\ Doutorado em Educação Ambiental \\ ORCID ID: https://orcid.org/0000-0001-7121-9921* \\ ORCID ID: https://orcid.org/0000-0003-0342-9331*
}

\begin{abstract}
Resumo
O artigo apresenta uma discussão acerca do conceito de Educomunicação Socioambiental no âmbito do ensino escolar infantil. Interface que surge da relação entre a Educomunicação e a Educação Ambiental, tal conceito será exposto a partir de uma sistematização bibliográfica, quando se torna possível encontrar as intersecções contemporâneas que surgem da utilização da tecnologia do audiovisual como mediação no processo de ensino-aprendizagem. Tal análise será feita levando em consideração o documentário 1,2,3 Brincando - Reinventando Espaços Escolares, produzido pela rede pública da cidade de Joinville, Santa Catarina, que traz um material audiovisual elaborado pelos estudantes. Ao realizar uma decupagem fílmica quantiqualitativa, emerge a potência pedagógica da Educomunicação Socioambiental, que acaba por trazer à cena uma linguagem e um conteúdo que projetam outra forma de pensar a escola. Por fim, cabe uma reflexão sobre como, a partir das especificidades, podem se elaborar políticas educacionais que contemplem a ferramenta do audiovisual no ensino infantil.
\end{abstract}

\section{Palavras-chave}

Educação Socioambiental. Audiovisual. Ensino infantil.

\section{Socioenvironmental Educommunication as a pedagogical strategy in early childhood education}

\begin{abstract}
This article discusses the concept of Socioenvironmental Educommunication in the context of preschool education. An interface that emerges from the relationship between Educommunication and Environmental Education, this concept will be exposed based on a bibliographic systematization, when it becomes possible to find the contemporary intersections that arise from the use of audiovisual technology as mediation in the teaching-learning process. Such analysis will be done taking into consideration the documentary 1,2,3 Playing - Reinventing School Spaces, produced by the city of Joinville, Santa Catarina, which brings an audiovisual material made by the students. Using a quanti-qualitative approach, emerges the pedagogical power of Socioenvironmental Education, which ends up bringing to the scene language and content that project another way of thinking the school. Finally, there is a reflection on how, based on particularities, it is possible to create educational policies that contemplate the audiovisual tool in early childhood education.
\end{abstract}

\section{Keywords}

Socioenvironmental Education. Audiovisual. Early childhood education. 


\title{
La Educomunicación Socioambiental como estrategia pedagógica en la educación infantil
}

\begin{abstract}
Resumen
El artículo presenta una discusión sobre el concepto de Educación Socioambiental en el ámbito de la educación preescolar. Interfaz que surge de la relación entre Educomunicación y Educación Ambiental, este concepto se expondrá a partir de una sistematización bibliográfica, cuando sea posible encontrar las intersecciones contemporáneas que surgen del uso de la tecnología audiovisual como mediación en el proceso de enseñanzaaprendizaje. Esta análisis se realizará teniendo en cuenta el documental 1,2,3 Reproducción - Reinvención de los Espacios Escolares, producido por la red pública de la ciudad de Joinville, Santa Catarina, que trae un material audiovisual realizado por los estudiantes. Al realizar un decoupage cuantitativo cinematográfico, emerge el poder pedagógico de la Educación Socioambiental, que termina por poner en escena un lenguaje y contenido que proyectan otra forma de pensar la escuela. Finalmente se reflexiona sobre cómo, a partir de los aspectos específicos, se pueden elaborar políticas educativas que contemplen la herramienta del audiovisual en la educación infantil.
\end{abstract}

\section{Palabras clave}

Educación Socioambiental. Audiovisual. Educación infantil.

\section{Introdução}

Quando um trem surge na tela, no ano de 1895, vários são os relatos das pessoas que, espantadas, fugiram do local em que a cena estava sendo projetada pelos Irmãos Lumière, na França. Anos depois, em 1902, George Méliès fazia com que uma viagem à Lua se tornasse possível através do cinema e que, assim, a ficção alcançasse plateias em um movimento que percorreria todo o século $X X$ caracterizando o cinema como arte integrante desse tempo histórico.

Dos equipamentos de grande porte às câmeras portáteis encontradas à venda em lojas do segmento passaram-se algumas décadas. $E$, já no final do século $X X$, um novo ponto de inflexão surgiu, o celular. Os registros de trens e viagens à Lua deram lugar a filmagens do dia a dia, entrando em cena um lugar em que tal tecnologia é tão presente: a escola (RELPH, 2014). Ou seja, a câmera agora está na mão dos estudantes.

E aqui inicia a discussão apresentada neste artigo, o qual se debruça sobre a potência pedagógica que possui a utilização da produção audiovisual no contexto escolar contemporâneo frente à popularização dos recursos audiovisuais no século XXI, problematização feita a partir do horizonte epistemológico da Educomunicação 
Socioambiental. Intersecção da Educomunicação (SOARES, 2011) com os fundamentos da Educação Ambiental (REIGOTA, 1994), tal terminologia surge a partir da compreensão de Munhoz (2019) como forma de interpretar produções cujo tema central trate das relações dos sujeitos com o ambiente.

Para que seja possível realizar essa discussão, será avaliado aqui o conjunto fílmico produzido pelos alunos da rede básica de ensino da cidade de Joinville, Santa Catarina (SC), os quais, no contexto de criação do documentário 1,2,3 Brincando Reinventando Espaços Escolares', puderam operar câmeras para contarem sobre a própria história acerca da escola. Ao criarem uma narrativa audiovisual, 12 crianças ${ }^{2}$ entre 5 e 6 anos de um dos Centros de Educação Infantil (CEIs) apresentam a potência na qual está assentada o uso do recurso tecnológico audiovisual no ambiente escolar.

Ao retomar os preceitos da Educomunicação, agora à luz dos fundamentos da Educação Ambiental, torna-se possível contribuir com um debate moderno na rede de ensino básico, que diz respeito aos sentidos pedagógicos que poderiam ser dados às tecnologias que atravessam a rotina escolar. E, para este trabalho, será efetuada uma abordagem quantiqualitativa, expressada a partir de um processo de revisão bibliográfica, bem como análise de conteúdo do material filmado pelos estudantes (SOARES, 2011; TRAJBER, 2005), propondo uma sistematização crítica capaz de fornecer subsídios para refletir e criar estratégias acerca desse tipo de recurso no ensino formal.

\section{Interfaces: Educomunicação e Educação Ambiental}

Discutir Educomunicação no Brasil é remeter ao nome do pesquisador Ismar Soares, da Universidade de São Paulo (USP). É dele que parte o desenho desse conceito que surge da intersecção entre Educação e Comunicação, quem, junto à dissertação de Rachel Aline Hidalgo Munhoz, quando entrevistado, revela que tal conexão se deu por perceber uma necessidade de discutir o papel das mídias em um ambiente de educação (MUNHOZ, 2019).

A origem desses estudos, para o pesquisador, iniciou-se na década de 1970, quando nos Estados Unidos surgiram pesquisas unindo o impacto da mídia e o

1 O documentário pode ser encontrado no link: https://www.youtube.com/watch?v=0Oc4eFg8lHQ\&t=1175s.

2 Os direitos de imagem de cada estudante encontram-se junto à Secretaria de Educação de Joinville-SC.

Educação \& Formação, Fortaleza, v. 5, n. 14, p. 54-72, maio/ago. 2020

DOI: https://doi.org/10.25053/redufor.v5i14mai/ago.1449

http://seer.uece.br/redufor 
comportamento dos sujeitos em sociedade (SOARES, 2014). Por sua vez no Brasil os trabalhos de Anísio Teixeira (1971) e de Paulo Freire (1983) também se inclinavam a pensar a radiodifusão como instrumento de comunicação importante para a Educação, o que, para Munhoz (2019), é identificado como Comunicação Popular ou Comunicação Alternativa.

Foi nessa última década do século $X X$ que as discussões ganharam força; não por acaso, pois foi o momento em que ocorreu a popularização de vários recursos tecnológicos que foram barateados, iniciando-se então uma aproximação com diferentes camadas sociais (TRIGUEIRO, 2005). Porém, ao pensar uma síntese que desse sentido a esse contexto que culminou com um delineamento científico do termo "Educomunicação", é possível dizer que esses estudiosos que começaram a integrar o campo da Comunicação nos seus trabalhos possuíam um horizonte comum, os quais podem ser assim colocados:

\begin{abstract}
O assunto pesquisado pelos estudiosos/as latino-americanos/as era identificado nos movimentos sociais que lutavam diante das ditaduras civis-militares, promovendo uma nova perspectiva sobre a intervenção social, caracterizando essa forma de dialogar nos meios, participando de rádios comunitárias, criando folhetins, boletins informativos, faixas, cartazes, panfletos, jornais e outros. (MUNHOZ, 2019, p. 32).
\end{abstract}

Como se pode perceber, o que está em jogo é uma comunicação popular, uma comunicação que é considerada bem público e que se manifesta desde a criação do material até a sua veiculação - reconhecendo o processo como elemento aglutinador. $E$, nesse percurso, a premissa central se torna o diálogo, a capacidade de comunicar algo entre todos os envolvidos em uma determinada especificidade em que se encontram - 0 que faz tal proposta emergir não só em espaços formais, mas sobretudo fora deles.

O trabalho desenvolvido por Ismar Soares no Brasil foi essencial para consolidar essa prática e, com isso, apresentar subsídios conceituais que culminaram, após a sistematização de um conjunto de referenciais teóricos e metodológicos, no neologismo "Educomunicação". Da junção da Educação com a Comunicação surge um campo de intervenção social que reivindica um "pensar diferente" (SOARES, 2011). Nas palavras do autor:

O conjunto de ações inerentes ao planejamento, implementação e avaliação dos processos, programas e produtos destinados a criar e a fortalecer ecossistemas 
comunicativos em espaços educativos, melhorar o coeficiente comunicativo das ações educativas, desenvolver o espírito crítico dos usuários dos meios massivos, usar adequadamente os recursos da informação nas práticas educativas e ampliar a capacidade de expressão das pessoas. (SOARES, 2003, p. 1).

Existe, tomando por base a posição conceitual de Soares (2003), uma vinculação à ideia de processo, de exploração de suportes que possam não criar comunicações-fim, mas sim mediadoras de saberes, uma comunicação início ou meio de, o que gera fortalecimento do que se chama de "ecossistemas comunicativos" em diversas esferas, incluindo a do ensino formal. O fomento crítico da Educomunicação vale-se dessa construção de informações que promovem acesso a temas diferenciados, os quais partem dos sujeitos em suas demandas locais e globais, assim como podem ampliar suas capacidades de expressão.

É possível perceber as aproximações com Paulo Freire, não só pela busca de uma comunicação verdadeira, baseada na democratização das formas de comunicação e recepção delas, mas pelo reconhecimento da obra freireana por parte do próprio Ismar Soares, o que também acontece por uma aproximação com a Educação Ambiental (EA), que está presente nas experiências do próprio pesquisador vinculado ao Núcleo de Comunicação e Educação da Escola de Comunicação e Artes da Universidade de São Paulo (NCE/ECA/USP), quando entende, por exemplo, a importância de ter participado da 1a Jornada Internacional de Educação Ambiental, em 1992, no Rio de Janeiro, para concepção do conceito de Educomunicação (MUNHOZ, 2019).

Tal evento ocorreu na capital do estado do Rio de Janeiro, em paralelo à $2^{\underline{a}}$ Conferência das Nações Unidas Sobre o Meio Ambiente e Desenvolvimento - Rio/92, e foi dele que surgiu um documento basilar ao campo da EA, o Tratado de Educação Ambiental para Sociedades Sustentáveis (MUNHOZ, 2019). Aqui se atenta para um dos princípios presentes nesse Tratado, que foi reconhecido internacionalmente:

\footnotetext{
A educação ambiental requer a democratização dos meios de comunicação de massa e seus comprometimentos com os interesses de todos os setores da sociedade. A comunicação é um direito inalienável e os meios de comunicação de massa devem ser transformados em um canal privilegiado de educação, não somente disseminando informações em bases igualitárias, mas também promovendo intercâmbio de experiências, métodos e valores. A educação ambiental deve integrar conhecimentos, aptidões, valores, atitudes e ações. Deve converter cada oportunidade em experiências educativas de sociedades sustentáveis. (TRATADO, 1992).
} 
Sugerir uma aproximação do trabalho desenvolvido por Ismar Soares com a consolidação da EA no Brasil não seria algo surpreendente. Ao contrário, seria reconhecer um percurso que permite perceber o diálogo da Educomunicação com os fundamentos da EA quando aponta para a democratização dos meios de comunicação de uma forma abrangente, compreendendo a comunicação como um direito de todos na busca de informações, mas também de trocas durante o processo.

O documento, então, faz com que esse vínculo, para além da evidente epistemologia freireana que atravessa a Educomunicação e a Educação Ambiental no âmbito da práxis de uma ação-reflexão-ação, manifeste-se como instrumento político. Ao surgir como forma de comunicação junto aos movimentos sociais, a Educomunicação não deixa de ser contemplada nesse mesmo Tratado de EA, quando pontua: "A Educação Ambiental não é neutra, mas ideológica. É um ato político, baseado em valores para a transformação social" (TRATADO, 1992).

Nos anos 1990, junto ao cenário da política educacional, lembra Rachel Munhoz (2019, p. 37), a Política Nacional de Educação (PNEA), que estava sendo gestada pelo Ministério da Educação (MEC), "[...] apontava para a essencial relação entre comunicação e meio ambiente, visando garantir a disseminação e acessibilidade de informações de temática ambiental". Com a chegada dos anos 2000, intensificavam-se as relações institucionais com o Ministério do Meio Ambiente, da mesma forma que a Educomunicação se consolidaria como curso superior na USP em 2009 (MUNHOZ, 2019).

Tais elos se fortaleceram a tal ponto que a expressão "Socioambiental" passa a ser corrente como adjetivação de um trabalho feito de forma conjunta. Na ementa desse novo curso, surge o seguinte entendimento sobre esse elemento:

\footnotetext{
A Educomunicação Socioambiental coloca-se como importante colaboradora para a compreensão e divulgação da Educação Ambiental, de modo que os alunos da Licenciatura em Educomunicação conheçam seus conceitos e possam tornar-se professores de comunicação e consultores na área da Educomunicação Socioambiental, dentre outras atividades. (USP apud MUNHOZ, 2019, p. 43).
}

A junção desses termos ganha uma primeira base, porém dá-se de forma vinculada ao campo da comunicação, como irá perceber Munhoz (2019) ao levantar o número de 292 pesquisas junto ao banco de Teses e Dissertações da Coordenação de Aperfeiçoamento de Pessoal de Nível Superior (Capes). Constam, segundo a pesquisadora, 30 trabalhos que abordam a inter-relação com a área da Educação 
Ambiental, sugerindo que a variação nos termos impede que seja percebida uma coesão nas abordagens que as pesquisas levam a cabo.

Assim, verifica-se em Munhoz (2019) o primeiro registro sistematizado dessa intersecção a partir de uma ampla revisão bibliográfica e de documentação institucional, bem como uma gama de categorias que surgem da análise do material fílmico presente no Circuito Tela Verde ${ }^{3}$, investigado por ela em seu trabalho. É possível encontrar, nesse sentido, uma discussão singular que faz com que a Educomunicação Socioambiental ganhe uma renovada interpretação frente ao atual momento de ampliação do acesso tecnológico e se consolide a partir do entendimento de que "[...] seja possível levar em conta que a Educomunicação, em posse de educadores/as ambientais, corresponderá sempre à Educomunicação Socioambiental" (MUNHOZ, 2019, p. 49).

Alinhavar tais elementos para propor alternativas no espaço escolar, seja quanto à utilização de suportes tecnológicos de mediação de saberes, como quanto à produção desses através de uma câmera ao alcance de todos através do celular, no qual a subjetividade a ser acessada esteja conectada a uma discussão ambiental, é o passo seguinte deste texto. Ao evidenciar a produção dos estudantes da rede pública de Joinville-SC, será possível encontrar aqui, insistindo no termo, a potência pedagógica que surge ao se conectarem áreas do conhecimento a partir de um sentido epistemológico, nesse caso, a Educomunicação Socioambiental.

\section{Quando a Educomunicação Socioambiental surge na tela}

O documentário 1,2,3 Brincando - Reinventando os Espaços Escolares foi produzido pelo grupo de pesquisa Ribombo, da Universidade Federal do Rio Grande (FURG), como parte do trabalho de formação continuada que possui com os professores da rede municipal de Joinville-SC desde o ano de 2017, quando a Secretaria Municipal de Educação passou a incorporar os Objetivos do Desenvolvimento Sustentável (ODSs) - oriundos da Organização das Nações Unidas (ONU), com uma agenda pactuada entre diversos países, inclusive o Brasil, até 2030 - como uma das premissas do seu projeto político-pedagógico e também como uma estratégia de gestão. Passaram a participar

3 Programa estatal de promoção do audiovisual ambiental. Para maiores detalhes de sua implementação pública, é possível acessar: http://www.mma.gov.br/educacao-ambiental/educomunicacao/circuito-tela-verde.

Educação \& Formação, Fortaleza, v. 5, n. 14, p. 54-72, maio/ago. 2020

DOI: https://doi.org/10.25053/redufor.v5i14mai/ago.1449

http://seer.uece.br/redufor 
dos processos formativos, na condição de replicadores nas suas respectivas unidades escolares, gestores e docentes dos 70 CEls, que, como multiplicadores, ajudaram a levar a formação a aproximadamente 2.000 profissionais da Educação que atuam na educação infantil, abarcando em torno de 22.000 alunos matriculados segundo os dados de 2018 da referida secretaria.

Durante os 26 minutos e 31 segundos do documentário em seu corte final, existe o que se pode considerar um outro documentário, que diz respeito a sete inserções que são realizadas pelos alunos de um dos CEls nas filmagens que ocorreram em 2018, os quais contabilizam 3 minutos e 78 segundos. Portanto, o que está em tela é o excerto filmado pelos estudantes, os quais refletem em sua experiência fílmica as relações que estabelecem com o meio, o qual passou por transformações no contexto do projeto continuado Reinventando Espaços Escolares, podendo ser acessados pelos registros que realizam.

Entregar a eles a câmera ocorreu como um ato espontâneo da produção do documentário, mas que projeta as premissas já trabalhadas no contexto formativo com o grupo de gestoras e professoras de Joinville-SC. E, em vez de procurar conexões diretas entre a formação continuada e o material analisado, a intenção é promover um debate sobre o que pode emergir justamente em instituições escolares que buscam alternativas contemporâneas de promoção do diálogo junto aos processos de ensino-aprendizagem.

Para analisar esse material, é realizada uma abordagem qualitativa, que, orientada por Nibaldo Triviños (1987), elenca uma premissa basilar quando reconhece a tendência de natureza desreificadora dos fenômenos, do conhecimento e do ser humano, assim como a rejeição da neutralidade do saber científico nesse tipo de enfoque. Nesse escopo, pensar tal perspectiva a partir do suporte do registro audiovisual e metodologias correspondentes compreende, então, que toda e qualquer interpretação não se inicia no ato filmado, mas começa no olhar sensível de quem efetuou o registro e no que isso pode revelar sobre o que foi escolhido a partir dessa experiência.

Segundo Penafria (2009, p. 1-2), a análise de um filme é realizada por meio da relação interpretativa entre o material e o seu pesquisador, assim: "[...] trata-se, acima de tudo, de uma actividade que separa, que desune elementos. E após a identificação desses elementos é necessário perceber a articulação entre os mesmos [sic]". Desse modo, como uma adaptação do que fora apresentado pela autora a partir das quatro 
modalidades de análise fílmica sistematizadas em seu trabalho, o material foi manejado a partir de segmentos que se relacionam dentro de três unidades dramáticas básicas (introdução, desenvolvimento e conclusão): 1 - localização; 2 - tempo de duração; e 3 assunto. Nesse sentido, o material audiovisual foi considerado um texto. Diante disso, a partir desta metodologia, busca-se apresentar o conteúdo da análise textual que as inserções audiovisuais das crianças implicaram ao filme. Tal procedimento levou à seguinte construção metodológica:

Quadro 1 - Elementos audiovisuais

\begin{tabular}{|c|c|c|c|}
\hline Momento & Localização & Tempo & Assunto \\
\hline Introdução & Pátio/árvores & $0-0^{\prime}: 07^{\prime \prime}$ & Pedido para filmar \\
\hline Introdução & $\begin{array}{c}\text { Pátio interno } \\
\text { Espaço pedagógico } \\
\text { Horta }\end{array}$ & $0^{\prime}: 16^{\prime \prime}-1^{\prime}: 03^{\prime \prime}$ & $\begin{array}{c}\text { Imitação de } \\
\text { Youtuber }\end{array}$ \\
\hline Desenvolvimento & $\begin{array}{c}\text { Horta } \\
\text { Pátio interno }\end{array}$ & $6^{\prime}: 53^{\prime \prime}-7^{\prime}: 09^{\prime \prime}$ & $\begin{array}{c}\text { Como a gente cuida } \\
\text { da gente mesmo e } \\
\text { entrevista sobre o } \\
\text { que gostam de } \\
\text { brincar }\end{array}$ \\
\hline Desenvolvimento & Pátio interno & $10^{\prime}: 30^{\prime \prime}-11^{\prime}: 13^{\prime \prime}$ & $\begin{array}{c}\text { Dançando e } \\
\text { cantando para a } \\
\text { câmera }\end{array}$ \\
\hline Desenvolvimento & Horta escolar & $16^{\prime}: 35^{\prime \prime}-18^{\prime}: 06^{\prime \prime}$ & $\begin{array}{c}\text { Simulação de um } \\
\text { canal no YouTube } \\
\text { sobre como cuidar } \\
\text { de plantas }\end{array}$ \\
\hline Desenvolvimento & Espaço pedagógico & $19^{\prime}: 20^{\prime \prime}-19^{\prime}: 38^{\prime \prime}$ & $\begin{array}{c}\text { Bincando no navio } \\
\text { espião, como } \\
\text { cobertura de } \\
\text { entrevista com } \\
\text { professora }\end{array}$ \\
\hline Final & Pexpedida \\
\hline
\end{tabular}

Fonte: Elaboração dos autores (2019).

Tal sistematização irá permitir um aprofundamento, a seguir, de cada sequência forjada pelos estudantes, as quais não possuíram trabalho de edição, sendo apresentadas ao longo do documentário. Dessa forma, abre-se o filme ao texto desses autores do audiovisual.

\section{Um filme a ser interpretado}

O documentário começa com uma criança dizendo: "É que eu queria filmar agora!". Em seguida, outra voz, também de uma estudante, intervém: "Espera”. Essa é a 
sequência de abertura, em que, logo que percebem que irão poder filmar a sua própria história, anunciam não só a existência de um vídeo sendo realizado, mas de um querer filmar - a quarta parede do audiovisual se rompe, e isso ocorre em meio ao apelo de uma nova autoria, que irá iniciar a partir dessa inflexão.

O ambiente escolar é o cenário; a câmera é a mediação técnica; os autores são as estudantes de um dos CEls envolvidas nesse filme, que revela a emergência não só desse tipo de tecnologia ou de um processo de transformação pedagógica na rede pública de Joinville-CE, mas sobretudo de um olhar sensível que se projeta sobre aquilo que se vê e como se vê. Há um olhar comunicando-se, e isso é um dos elementos de todo e qualquer diálogo.

Ao pensar primeiro na linguagem que estabelecem através desse suporte, é possível dizer que ela é carregada de experiências calcadas no seu cotidiano, e isso se torna evidente pelo fato de que, ao tomar a câmera no formato selfie e iniciar a apresentação de um grupo de alunos no pátio do $\mathrm{CEI}$, a estudante-apresentadora diz: "Todo mundo olhando pra câmera! Oi, galerinha do Youtube".

Essa é uma expressão usual no universo dessa plataforma de streaming de vídeos, sendo comum que crianças assistam aos conteúdos produzidos para esse tipo de canal de comunicação e, portanto, incorporem linguagens tanto gestuais como orais desse ambiente virtual. Ainda cabe lembrar que usuários dessa plataforma podem criar suas próprias contas, o que faz com que existam tanto uma relação de espectador como também uma de produtor junto ao público infantil, demonstrando o que, no início deste texto, foi mencionado como ideia de construção visual do mundo (LEÃO; PRESSLER, 2017).

Reconhecer esse acúmulo que já está nos estudantes é um primeiro passo ao pensar estratégias de Educomunicação Socioambiental que possam ser implementadas em escolas, ao mesmo tempo que é preciso estar preparado para a ausência de linguagens prévias, o que faz com que a surpresa também apareça, já que horizontes inesperados podem se abrir no uso desse recurso pedagógico. Porém, em ambos os casos, estaremos diante do mesmo elemento que os une e que a sequência de abertura faz com que se perceba: o nível de altura física da filmagem.

Isso é algo que poderia passar despercebido, mas, quando entendemos que efetivar essa descida da câmera ao nível do olhar infantil, cria-se uma nova dimensão a 
ser explorada, e imediatamente encontramos um ponto de vista sendo construído. Ele pertence aos estudantes em sua forma de observar a escola, colocando a câmera na proporção de suas alturas físicas. Desse modo, o que surge é outra escola.

Ao anunciar "Eu tô filmando!", a estudante logo filma o rosto de outra colega, que, incrédula, pergunta: "Sério?". A surpresa da filmagem também ocorre entre eles, mas a câmera segue em um plano-sequência que leva até a horta escolar, demonstrando, assim, os lugares para os quais elas, as crianças, desejam apontar os seus interesses a serem revelados ao público. E o que querem mostrar, ao contrário do que podíamos esperar, é uma horta baseada no detalhe, no foco, em uma relação com um item em especial: o "tomatinho" cuidado por uma delas. Ao contrário de uma explicação sobre o ambiente, o que ocorre é um protagonismo envolto a um conceito de cuidado, que, em sua concepção, deve permear esse espaço.

Após esse grupo de interpretações que compõe o bloco considerado como "Abertura", o desenvolvimento do documentário filmado por eles expõe uma câmera operada por uma das alunas que segue os comandos da "apresentadora", quem, já na primeira frase, anuncia: "Agora a gente vai falar da gente mesmo", pedindo a câmera para segui-la.

A dimensão da autofilmagem funciona como um trem, como uma viagem à Lua ou como um embarque em algo a ser explorado por esses estudantes, que reivindicam o reconhecimento da autoria e dos seus pares na escola. Nota-se também que surge a noção de escola/lugar como um elemento que não precisa necessariamente ser nomeado nesse início de filmagem. Ao contrário disso, na narrativa que eles criam o que se concebe como ambiente escolar é orgânico a eles, é uma extensão de si, portanto não é um outro alheio que precise ser apresentado.

Em outras intervenções fílmicas das crianças, quando se repete o estilo de um operador de câmera e apresentação de forma dinâmica, surgindo espontaneamente os elementos do processo em curso, é dito pela apresentadora em direção a uma colega: "Canta uma música". Sem titubear, a garota inicia uma canção que, naquele momento, em 2018, era recorrente em rádios e plataformas de áudio, assim como na televisão, mostrando uma presença na câmera que, antes de qualquer sugestão de constrangimento, evidencia interesse com o pedido da colega. 
Estar sendo filmada pela própria colega parece estabelecer uma proximidade que, dada a corporeidade da faixa etária, as coloca no mesmo de nível de visão, de relação entre olhares que possuem, como mediação pelas lentes de uma câmera. Se pensarmos que, para fazer o mesmo, um adulto precisaria estar ou filmando do seu ponto de vista, que é de uma altura superior, ou então se ajoelhando, em um desconforto evidente em relação ao corpo, estar diante de um olhar nivelado, de igual proporção, faz com que apareçam espontaneidades singulares.

A escolha em fazer intervenções diretas com o grupo por parte da apresentadora ainda reserva uma sequência de dança com outra música, dessa vez adaptada para fins pedagógicos, certamente veiculada na escola, em que três alunas fazem as vezes de intérpretes. Em dado momento quem opera a câmera opta por inverter a situação e com isso iniciar a modalidade visual de selfie, cantando e dançando junto com as demais crianças presentes na filmagem.

Nesse ato que traz a empolgação de quem filma e de quem não deseja ficar de fora daquele momento, rompem-se algumas barreiras de participação. A existência de uma câmera, então, não significa um afastamento, mas uma aproximação, já que a qualquer momento a objetiva que aponta para algo pode ser invertida; isso não está como um problema, mas como uma solução, que, de forma mais justa, enquadra a todos no ambiente. Afinal, o aparelho de registro audiovisual não é nenhuma novidade para tal geração, pelo contrário, é, muitas vezes, o suporte comumente utilizado para fins comunicativos.

Recriando a sua versão de canal do YouTube com a câmera, as alunas apresentam o que chamam de um "vídeo sobre plantas" e mostram a história de uma planta que aparentemente estaria "morta". Elas fazem isso através de um close, o que salienta o objeto mostrado, com uma aproximação que traz algum tipo de sensação em relação a ele. Tal movimento alcança efeito quando as crianças anunciam a mudança do close para outro ponto de vista, fazendo com que o equipamento as mire, mais uma vez, elas mesmas, em um diálogo direto com o espectador. A modalidade da comunicação que ocorre com maior aproximação entre emissor e receptor da mensagem caracteriza a sequência em grande relevância, já que se trata do trecho com maior tempo de duração entre todas as inserções realizadas pelas crianças. 
A tarefa ficará a cargo da "turma", que irá conseguir impedir a morte de mais plantas. Para mostrar isso, a câmera faz um rápido giro, quando surge uma criança que, ao realizar uma expressão para chamar a atenção na filmagem, quebra as regras desse "programa" que está sendo gravado. A figura, por mais rápida que surja, diz muito sobre o que está em processo, já que evidencia uma construção de linguagem pactuada entre os estudantes, com suas próprias referências, com seus próprios saberes, que apontam para a melhor forma de elaborar essa mensagem, que, no caso, diz respeito ao salvamento das plantas da escola.

Ao destoar da filmagem, tal cena evidencia a autoria da produção, e assim é possível entender que estamos diante de uma linguagem que é criada para comunicar-se entre si. A "galerinha do YouTube" é esse outro para quem elas falam, porém falam a partir de si, portanto criam um canal sensível de comunicação, forjam um diálogo que só é possível existir como tal a partir do uso da câmera, que gera essa troca de referências.

Ainda nessa mesma sequência, acompanhamos a exposição de três mudas de plantas que são colocadas em uma mesa, encenando uma apresentação ao espectador. A criação dessa situação repercute a concepção audiovisual de expor comparações e linearidades didáticas para alcançar o entendimento do público, o que se evidencia na atitude das crianças ao mostrarem as fases de uma planta, valendo-se justamente dessa estratégia pedagógica como forma de passar uma mensagem.

Já se encaminhando ao final, na sequência filmada pelos estudantes dentro de uma réplica de navio, a qual serve como finalidade pedagógica no pátio de um dos CEls, um ângulo inusitado surge; inusitado não só para quem assiste, que percebe a situação do ponto de vista do estudante que opera a câmera em primeira pessoa, mas principalmente para quem percebe a relação visual que se estabelece com uma adulta sendo filmada por essa criança. O olhar de surpresa da pessoa adulta captado pela câmera que o aluno maneja ao registrar a atividade que está acontecendo dentro desse navio denota o estranhamento que está em jogo. Se espontaneidade é o que perpassa pelos olhares nivelados, é esse comportamento estranhado que vem à tona quando a dimensão é outra, quando a câmera está em uma posição inesperada, de baixo para cima, da mesma forma que manejada por uma criança.

A última sequência é apresentada pelas crianças seguindo um formato de despedida, em que uma delas opera a câmera e outra acena para a "galera" dando um 
"tchau". Assim, encerra-se a criação de um material audiovisual produzido pelos estudantes, que mostra não só o que eles veem, mas como veem, além das estratégias que utilizam para comunicar isso.

Levando em consideração que o projeto Reinventando os Espaços Escolares possui como elemento central uma reorientação da utilização dos espaços escolares sob o ponto de vista epistemológico da Educação Ambiental e da Educomunicação, é preciso evidenciar o conjunto de intersecções discutidas aqui. Por isso, sistematiza-se a seguir o quadro em que, a partir de um suporte de comunicação/tecnologia, seja possível perceber a similaridade de fundamentos que permitem pensar uma Educomunicação Socioambiental:

Quadro 2 - Interfaces

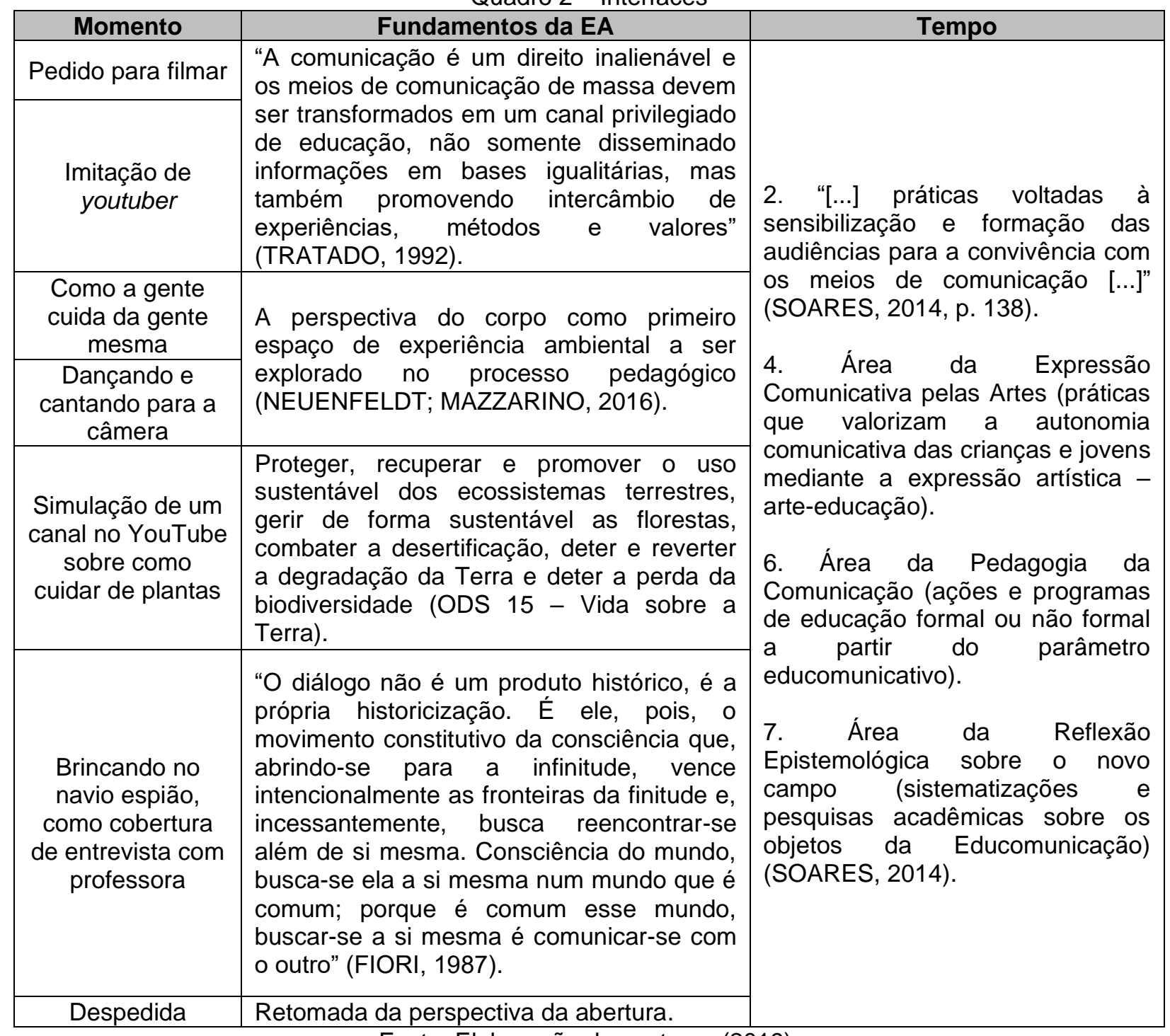

Fonte: Elaboração dos autores (2019).

Educação \& Formação, Fortaleza, v. 5, n. 14, p. 54-72, maio/ago. 2020

DOI: https://doi.org/10.25053/redufor.v5i14mai/ago.1449

http://seer.uece.br/redufor 
Como é mostrado no Quadro 2, a EA se particulariza a cada categoria, quando fundamentos específicos corroboraram uma abordagem ambiental que está sendo realizada pelos estudantes. Enquanto isso, a Educomunicação se dispõe de maneira integral a todas as categorias, pois permeia as diferentes etapas do documentário em um fluxo epistemológico e metodológico elencado por Ismar Soares (2014).

Dito isso, essas são categorias criadas após analisar o material fílmico, quando se torna possível desdobrar o audiovisual elaborado no âmbito dos fundamentos da intersecção aqui proposta. A Educomunicação Socioambiental, como interface, emerge no momento em que elementos basilares do campo da EA, encontrados já na adoção desse suporte/câmera, coadunam-se com os itens 2 e 4 da proposta de sistematização dos fundamentos da Educomunicação.

$O$ engajamento que demonstram de si no ambiente percorre a filmagem como expressão; está no registro cênico essa relação do uso do recurso para emitir o que passa a ser a sua autonomia, a qual se faz presente ao demonstrar sua grafia própria da escola, dos espaços, das formas de se relacionar com eles junto com colegas. O conteúdo se conecta à câmera através dos seus operadores; uma linguagem é construída e evidencia seus autores em um diálogo que expõe uma arte de mostrar a si no processo, em uma associação que remete ao item 4 da Educomunicação.

Quando um dos princípios do Tratado (1992) fala sobre a democratização da comunicação, o alcançar o maior número possível de pessoas a partir das mais variadas estratégias, o que está em jogo é também os suportes em que isso pode ser feito. $E$ aqui se retoma a relevância do evento da Rio-92 nos (des)caminhos do pesquisador que delineou o conceito de Educomunicação, já que ele vivenciou esse momento e também inspirado por ele - passou a trilhar um rumo epistemológico que levaria em consideração a premissa de comunicação presente nesse documento.

Por isso, cabe dizer que explorar os itens 6 e 7 acima elencados é trazer à discussão o papel dos docentes, os quais precisam pensar nos termos de uma Pedagogia da Comunicação (SOARES, 2014). E tal processo reflexivo, que deve fazer parte da Educomunicação Socioambiental nas escolas, pode ser encontrado, por exemplo, no processo formativo que ocorre junto à rede municipal de docentes de Joinville-SC.

Implementar uma política continuada em que alternativas pedagógicas possam facilitar a construção de uma comunicação verdadeira dentro da comunidade escolar, 
independentemente do suporte, que aqui é uma câmera, e a exploração do audiovisual a partir da sugestão de um campo do conhecimento parecem ser pontos comuns à realidade da educação brasileira nos dias atuais. O que pode ser encontrado na produção são possibilidades, as quais estão vinculadas a uma epistemologia que traz em si compreensões e práticas conectadas a essa demanda que atravessa as redes básicas de educação.

Se o uso de um telefone móvel nas escolas, que possui o recurso do audiovisual, pode ir além de uma representação negativa, é justo que isso seja feito a partir de saberes que podem ser acessados por esse mesmo dispositivo, que se torna elo de diálogo entre os atores sociais desse contexto. No documentário 1,2,3 Brincando..., pode-se ver os resultados de um esforço continuado da rede pública, mas pode-se observar sobretudo como tais resultados podem alcançar os estudantes quando eles lidam com suportes em que o audiovisual pode ser explorado.

\section{Considerações finais}

Quando fala sobre "educar ambientalmente", Rachel Trajber (2005, p. 152) explica: "[...] o que pouca gente sabe é que os conteúdos da Educação Ambiental fazem parte das origens brasileiras desse novo campo de pesquisa acadêmica e intervenção social que promove práticas democráticas e transformadoras de comunicação".

Depois de 15 anos dessa citação, talvez já seja possível dizer que mais gente saiba dessa conexão. E tal perspectiva é posta no trabalho de Munhoz (2019), quando concebe um processo de estado da arte junto a essa interface entre Educação Ambiental e Educomunicação, a qual é chamada de Educomunicação Socioambiental. Se há um princípio que parece unir esses saberes, talvez a síntese de Paulo Freire (1996, p. 91) possa ser aqui utilizada: "[...] a educação é comunicação, é diálogo [...] um encontro de sujeitos interlocutores que buscam a significação dos significados". É disso que se fala quando o assunto é Educomunicação Socioambiental e derivam disso as especificidades que passam a ser elaboradas dentro do processo que pode surgir no contexto do ensino formal.

A experiência em Joinville-SC mostra um trajeto que lança um novo olhar sobre a bibliografia constituída sobre o tema, consolidando a Educomunicação Socioambiental 
dentro de um espectro da EA. Ao interpretar o filme produzido pelos estudantes a partir de uma decupagem de forma e conteúdo, foi gerado um processo de sistematização capaz de acentuar as potências pedagógicas do uso de tecnologias audiovisuais na escola.

A forma como isso pode ser feito se projeta pelo reconhecimento das especificidades de cada contexto de ensino, que pode elencar as suas demandas em prol de uma agenda capaz de abarcar a temática ambiental. Com uma postura de mediação a partir do audiovisual, o que ocorre é a autonomia da linguagem da imagem e som sendo construída pelos estudantes, pelas suas referências, o que torna possível elaborar um diálogo verdadeiro, uma comunicação real e efetiva que se dá entre os sujeitos envolvidos no processo. Seja no início, quando o docente opta e precisa efetivar seu planejamento, seja em meio ao momento das filmagens, quando se revelam as representações sensíveis com e sobre o ambiente, seja ainda no final, quando todos assistem e podem dotar de significados tudo que foi registrado, entra em curso algo que remete ao trem que surge desenfreado na tela ou a uma incrível viagem à Lua.

A surpresa do espectador é a certeza do impacto. O inédito produzido pelos estudantes passa a ecoar no ambiente escolar, em que todos podem ser os autores de uma história que recomeça a cada dia.

\section{Referências}

BRASIL. Programa de Educomunicação socioambiental: comunicação popular e educação. Brasília, DF: Ministério do Meio Ambiente, 2008.

FIORI, E. M. Prefácio. In: FREIRE, P. Pedagogia do oprimido. 17. ed. Rio de Janeiro: Paz e Terra, 1987. Prefácio.

FREIRE, P. Extensão ou comunicação?. 7. ed. São Paulo: Paz e Terra, 1983.

FREIRE, P. Pedagogia da autonomia. São Paulo, Paz e Terra, 1996.

LEÃO, D.; PRESSLER, N. Youtuber mirim e o consumo infantil. In: CONGRESSO BRASILEIRO DE CIÊNCIAS DA COMUNICAÇÃO, 40., 2017, Curitiba. Anais... Curitiba: Intercom, 2017. p. 1-14.

MUNHOZ, R. A. H. Mar à vista da Educomunicação Socioambiental: apropriações socioambientais da zona costeira no Circuito Tela Verde (Edição de estreia). 2019. 167 f. 
Dissertação (Mestrado em Educação Ambiental) - Programa de Pós-Graduação em Educação Ambiental, Universidade Federal do Rio Grande, Rio Grande, 2019.

ONU - Organização das Nações Unidas. 17 Objetivos do Desenvolvimento Sustentável (ODS's). Disponível em: https://nacoesunidas.org/pos2015/agenda2030/. Acesso em: 12 jul. 2019.

PENAFRIA, M. Análise de filmes - conceitos e metodologia(s). In: CONGRESSO SOPCOM, 6., 2009. Disponível em: http://www.bocc.ubi.pt/pag/bocc-penafria-analise.pdf. Acesso em: 10 jul. 2019.

REIGOTA, M. O que é educação ambiental?. São Paulo: Brasiliense, 1994.

RELPH, E. Reflexões sobre a emergência: aspectos e essência do lugar. In: MARANDOLA JÚNIOR, E.; HOLZER, W.; DE OLIVEIRA, L. (Org.). Qual o espaço do lugar: geografia, epistemologia, fenomenologia. São Paulo: Perspectiva, 2014. p. 17-32.

SOARES, I. O. Alfabetização e Educomunicação: o papel dos meios de comunicação e informação na educação de jovens e adultos ao longo da vida. 2003. Disponível em: https://www.usp.br/nce/aeducomunicacao/saibamais/textos/. Acesso em: 27 jun. 2019.

SOARES, I. O. Educomunicação: o conceito, o profissional, a aplicação: contribuições para a reforma do ensino médio. São Paulo: Paulinas, 2011.

SOARES, I. O. Educomunicação e Educação Midiática: vertentes históricas de aproximação entre Comunicação e Educação. Revista Comunicação \& Educação, São Paulo, v. 19, n. 2, p. 15-26, 2014 . Disponível em: http://www.revistas.usp.br/comueduc/article/view/72037. Acesso em: 20 mar. 2020.

TEIXEIRA, A. Cultura e tecnologias. Rio de Janeiro: Fundação Getúlio Vargas, 1971.

TRAJBER, R. Educomunicação para coletivos educadores. In: FERRARO JÚNIOR, L. A. (Org.). Encontros e caminhos: formação de educadoras(es) ambientais e coletivos educadores. Brasília, DF: MMA, 2005. p. 149-158.

TRATADO de Educação Ambiental para Sociedades Sustentáveis e Responsabilidade Global. Rio de Janeiro, v. 9, 1992. Disponível em: http://www.mma.gov.br/educacaoambiental/politica-de-educacao-ambiental/documentos-referenciais/item/8068-tratado-deeduca\%c3\%a7\%c3\%a3o-ambiental-para-sociedades-sustent\%c3\%a1veis-e-responsabili dade-global.html. Acesso em: 9 jun. 2019.

TRIGUEIRO, A. Mundo sustentável: abrindo espaço na mídia para um planeta em transformação. São Paulo: Globo, 2005.

TRIVIÑOS, N. Introdução à pesquisa em ciências sociais: a pesquisa qualitativa em educação. São Paulo: Atlas, 1987. 


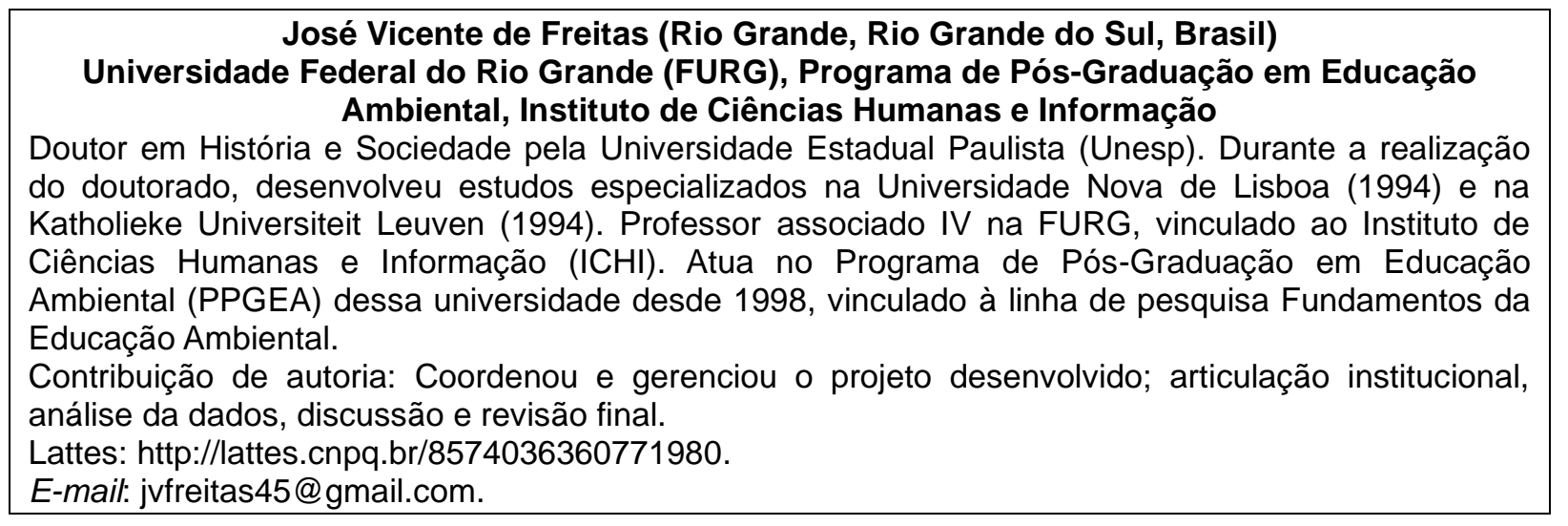

Felipe Nóbrega Ferreira (Rio Grande, Rio Grande do Sul, Brasil)
Universidade Federal do Rio Grande (FURG), Programa de Pós-Graduação em Educação
Ambiental, Doutorado em Educação Ambiental
Graduado em História pela FURG, mestre em História pela Universidade Federal do Rio Grande do
Sul (UFRGS) e doutorando em Educação Ambiental pela FURG. Integrante do Grupo de Pesquisa
Ribombo (PPGEA/FURG), trabalhando com práticas pedagógicas em contexto formal e informal, bem
como desenvolvendo pesquisa voltada aos estudos de fenômenos ambientais costeiros.
Contribuição de autoria: Coletou e analisou os dados e apresentou a discussão dos resultados.
Lattes: http://lattes.cnpq.br/6744281843415520.
E-mail: ffnobregaea@gmail.com.

Editora responsável: Lia Machado Fiuza Fialho Pareceristas ad hoc: Andrea Astigarraga e Angela Mara Lara

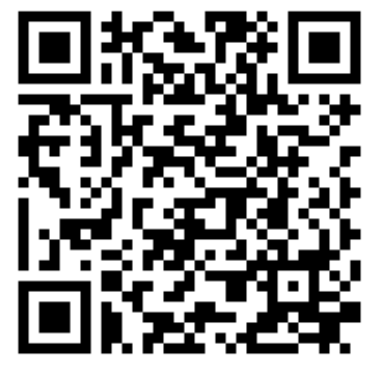

Recebido em 21 de julho de 2019.

Aceito em 08 de janeiro de 2020. 